\title{
Inequities in coverage of smokefree space policies within the United States
}

\author{
Christopher Lowrie ${ }^{1}$, Amber L. Pearson ${ }^{2,1,3^{*}}$ and George Thomson ${ }^{2}$
}

\begin{abstract}
Background: Previous studies have found extensive geographic and demographic differences in tobacco use. These differences have been found to be reduced by effective public policies, including bannning smoking in public spaces. Smokefree indoor and outdoor spaces reduce secondhand smoke exposure and denormálize smoking.

Methods: We evaluated regional and demographic differences in the proportion of the population covered by smokefree policies enacted in the United States prior to 2014, for both adults and children.
\end{abstract}

Results: Significant differences in coverage were found by ethnicity, region, income, and education $(p<0.001)$. Smokefree policy coverage was lower for jurisdictions with higher proportions of poor households, households with no high school diploma and the Southeast region. Increased ethnic heterogeneity was found to be a significant predictor of coverage in indoor "public spaces generally", meaning that diversity is protective, with differential effect by region ( $p=0.004)$ - which may relate to urbanicity. Children had a low level of protection in playgrounds and schools $(\sim 10 \%$ covered nationwide) - these spaces were found to be covered at lower rates than indoor spaces.

Conclusions: Disparities in smokefree space policies have potential to exacerbate existing health inequities. A national increase in smokefree policies to protect children in playgrounds and schools is a crucial intervention to reduce such inequities.

Keywords: Smoking, Inequalities, Smokefree spaces, Geography

\section{Background}

Tobacco use continues to be a primary global health issue, with over 180 nations committed to reducing smoking as signatories to the Framework Convention on Tobacco Control [1]. Cigarette smokers have shorter lifespans than non-smokers by at least 10 years [2], due to many health issues, including cancer, cardiovascular diseases, and respiratory diseases [3]. The negative effects of cigarette smoking are large and well-documented for most countries. In the United States, more people have been prematurely killed by cigarette smoke than in all of the nation's wars combined [2]. In the United Kingdom, $19 \%$ of cancer cases are linked with exposure to cigarette smoke [4]. And in China, alone, approximately one million deaths are linked to cigarette smoke each year [5].

* Correspondence: apearson@msu.edu

${ }^{2}$ Department of Public Health, University of Otago, Wellington 6021, New Zealand

'Department of Geography, Environment, and Spatial Sciences, Michigan State University, East Lansing, Ml 48824, USA

Full list of author information is available at the end of the article
Globally, tobacco kills more than six million people each year [1].

These impacts are distributed unequally, with consequent inequities. For this work, we adapt a definition of inequalities as 'the different availability of resources to which individuals and groups have access to' [6]. A range of studies have found evidence of inequities in tobacco smoking and secondhand smoke (SHS) exposure $[5,7,8]$, with minorities generally experiencing higher risks related to tobacco. Research in the United States revealed differences in likelihood of smoking by ethnicity, which became larger with age [9]. Another study in the United States found that smokefree home policies were more prevalent in the West, and among those making over $\$ 100,000$ and those with graduate degrees [10]. A study in the Southeastern United States found that less-educated citizens were less likely to be covered by smokefree space policies, and that smoking was a predictor of dropping out of high school [11]. In addition to ethnic differences, the likelihood of tobacco addiction has been associated 
with educational attainment, socioeconomic status, and region [5, 11-13]. In a study of American twins in the military, cigarette smoking was found to have an association with lower educational attainment [12]. Geographically, in the United States in 2015 the Midwest had the highest prevalence of cigarettes smoking among adults 18 years and older at $18.7 \%$, above the national prevalence of $15.1 \%$, and the southeastern states of West Virginia and Kentucky had prevalences of 26.7 and 26.2\%, respectively [8]. These inequities in smoking prevalences by ethnicity, socioeconomic status, and geography suggest drastically different tobacco related risks within America, dependent on circumstances and experience. To counter this, more widespread policies to cover vulnerable populations are needed.

Research has consistently found that denormalizing smoking is an effective way of decreasing smoking prevalence and preventing initial uptake of tobacco use [14-17]. To denormalize smoking is to reduce its social acceptability and the perception of it as a normal activity, thereby promoting quitting and preventing initiation [18]. Research indicates that interventions aimed at reducing tobacco use are more successful if they change what is considered socially 'normal' behavior within the targeted community. Many factors influence the normality of smoking, both positively and negatively. Smoking can be made to seem more normal due to advertisements and efforts by the tobacco industry, which spent $\$ 9$ billion on advertising in 2014, largely aimed at ethnic minorities [19]. Of importance to the current study, smoking can also be denormalized)by intelligent indoor and outdoor smokefree space policies. These policies reduce smoking in the public view, and have been shown to deter smoking and increase the perception of smoking as socially unacceptable $[20,21]$.

One important area of intervention is tobacco use by children, when lifetime use and addiction is typically established [22]. Smokefree space policies protecting places frequented by children are also important for reducing exposure to SHS. Almost half of children worldwide are regularly exposed to SHS in public spaces [1]. Extensive research has found smokefree space policies to be effective in reducing tobacco smoking and increasing cessation, while improving population health and air quality [23]. In California, smoking bans in homes and perceptrons of local smokefree outdoor areas were both found to decrease smoking and increase quit attempts [24]. Across the USA, smokefree indoor policy bans were also found to explain smoking prevalence at the state level [25]. In Ontario, exposure to smoking in restaurants and bar patios was found to decrease the likelihood of a quit attempt [26]. Jurisdictions in North America are increasingly adopting legislation for smokefree public spaces; a study in Canada found that indoor smoking restrictions follow a spatial diffusion pattern, with jurisdictions following examples set by nearby and similar jurisdictions [27].

While indoor smoking bans have been widely enacted since 1975 in the United States [28], outdoor smokefree policies are less common. Despite the compilation of a national database on both indoor and outdoor smokefree space policies in the United States [29] analysis of these important interventions remains limited. WWe found few existing national studies in the USA on regional differences in smokefree space policies, or on ethnic, socioeconomic, and educational differences in the populations covered by these policies. Studies have been conducted at the state level (e.g. California [30]), or have been limited to parks and beaches $[31,32]$. In the latter research, the odds of having a local smokefree parks policy were found to increase with higher percentages of Hispanics, people under the age of 18, Democrats, and recent movers; and to decrease with a higher percentage of older voters, smokers, and non-Hispanic Whites [32]. Additionally, lower ødds of having a smokefree space policy at the state level was significantly associated with higher percentages of smokers, and rural counties were found to be less likely to have policy protection than urban counties. Using policy data enacted up to 2009, Gonzales et al. found ethnic differences in coverage by indoor smokefree policies in the USA, with Hispanics and Asians having more coverage than Blacks [33].

Our research investigated inequalities in coverage by ethnicity, socioeconomic status, educational attainment, and region, for smokefree space policies covering school grounds, playgrounds, the indoors of restaurants and workplaces, and "indoor public spaces generally". The research questions were: 1) Are there differences in the proportion of the population covered by smokefree space policies by ethnicity, income, or education?; 2) Are there differences by ethnicity in the proportion of children covered by smokefree space policies for spaces often frequented by children (restaurants, school grounds, playgrounds, and indoor "public spaces generally")?; 3) Are there regional differences or geographic patterns in the proportion of the population covered by smokefree space policies?; and 4) What is the association between the existence of smokefree space policies covering all indoor public spaces and area-level ethnic heterogeneity, income, educational attainment, percentage white, and region?

\section{Methods}

\section{Data sources}

Tobacco control laws data were provided by the American Nonsmokers' Rights Foundation U.S. Tobacco Control Laws Database. This database contained zip code $(n=1574)$, county $(n=279)$, and state $(n=37)$ level data 
for policies enacted pre-2015 covering indoor and outdoor public spaces. Explicit in these data were descriptions of the policies and the spaces covered which were used in our analysis. Also included in these data were comments and policy descriptions, which were searched for keywords for indoor spaces: "restaurants", "workplaces", and "public spaces generally". In total, seven groups of restriction were studied: playgrounds, school grounds, both playgrounds and school grounds, indoor areas of restaurants, indoor areas of workplaces, indoor 'public spaces generally', and 'any of these policies'. We excluded smokefree policies covering less frequently visited spaces and places where less time would be spent (e.g., fairs/festivals, public events, and parking lots). State and county policies were applied to all zip codes within the jurisdiction to allow for analysis at the zip code level, resulting in a total of 21,477 zip codes with policies (66\% of the US total zipcodes). This builds on the work done and methodology used by Hood et al. [32], in which research was conducted at the county level. By using zip codes, we hoped to obtain a higher resolution of the differences between jurisdictions.

Demographic data were obtained from the US Census (2010) and included age, ethnicity, educational attainment, and income at the zip code level. Income data was used to calculate income quartiles. Each zip code was assigned to one of six regions, based on the state in which it is located (Figs. 1 and 2). By doing this, we hoped to improve upon the work done by Gonzalez et al. [33] by updating their 2009 analyses on ethnic inequalities and extending analyses to examine socioeconomic, educational, and regional inequalities. Ethnic heterogeneity was calculated as 1 minus the sum across ethnic groups of their respective squared proportion, as described by Wadsworth and Kubrin [34], and a binary high versus low ethnic heterogeneity/ variable was created using the mean as the cutoff.

\section{Statistical and geographic methods}

To address the first three research questions, a chisquared test was used to test for significant differences in counts of population subgroups covered by each of the seven types of smokefree space policies. Analysis was conducted by ethnicity (for the total population and for children $<15$ years old), income and educational attainment (for adults $\geq 25$ years old), and region (for the total population). To assess geographic patterns in policy adoption, data were imported into ESRI ArcGIS version 10.2 and maps for all zip codes, delineated by region, were created.

To address the fourth research question, we fitted a mixed effects logistic regression model, to test which demographic characteristics were associated with

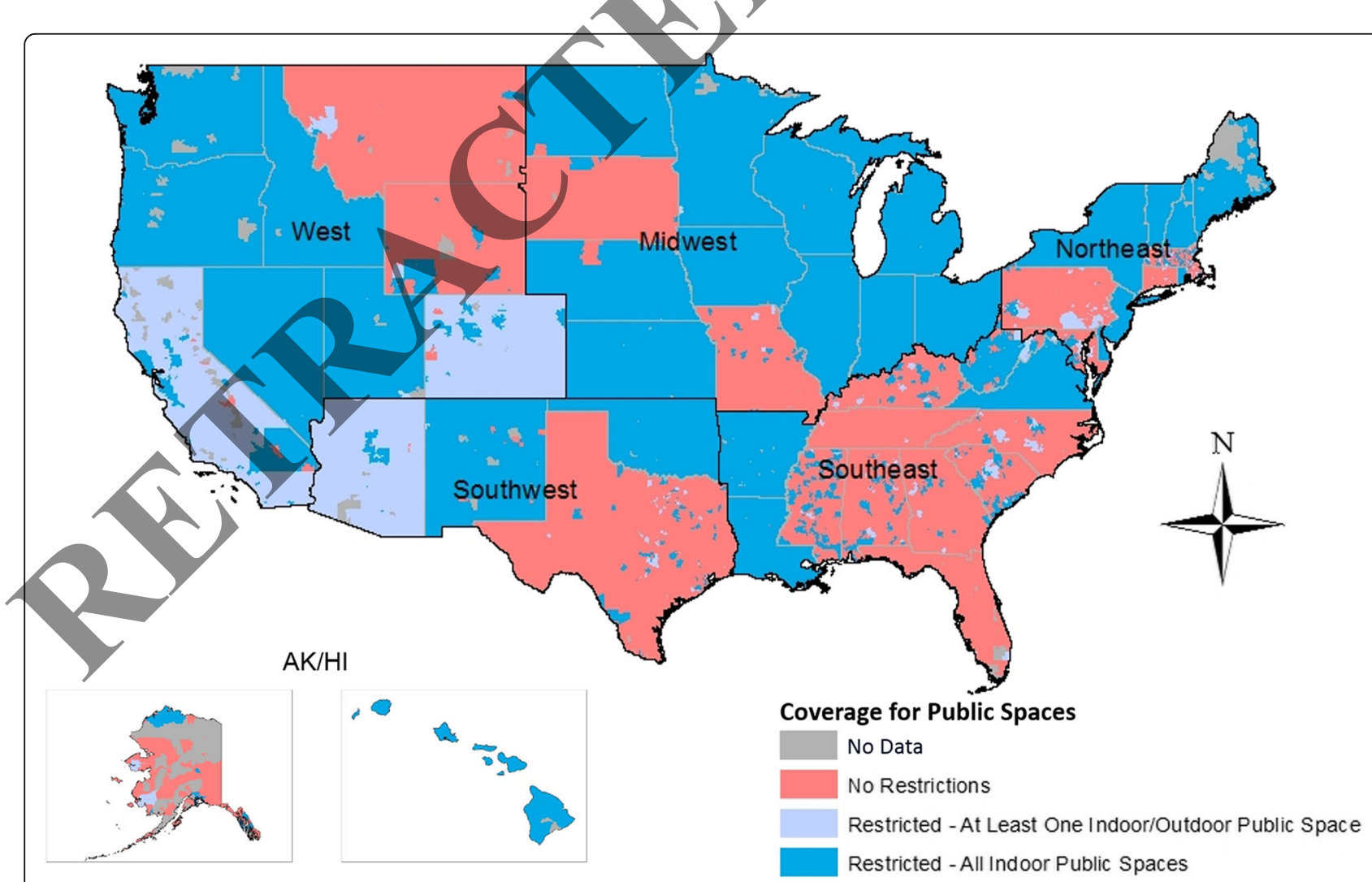

Fig. 1 The presence of smokefree space policies for none, at least one, or all indoor public spaces by region; map created by the authors 


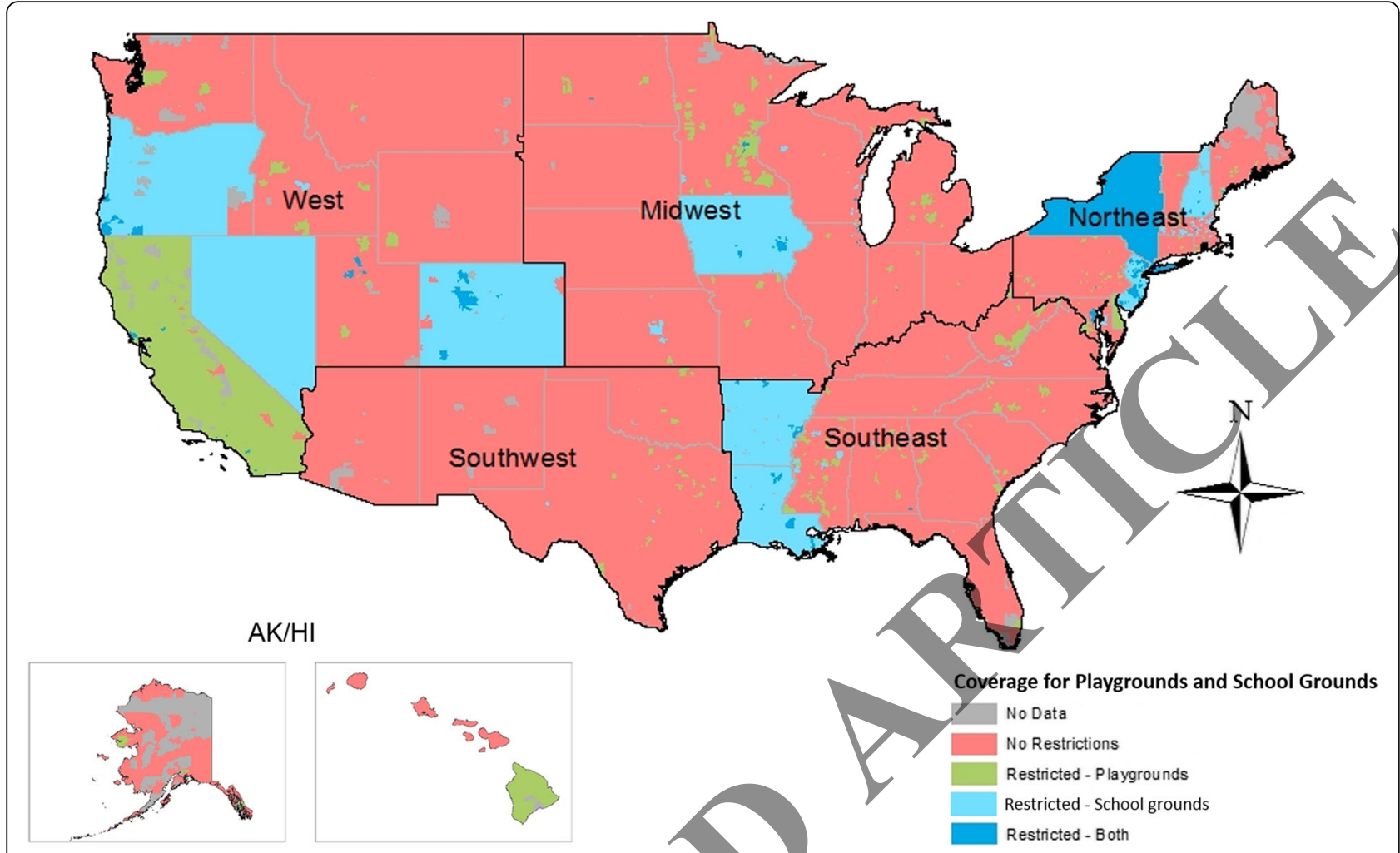

Fig. 2 The presence of smokefree space policies for school grounds, playgrounds, both, or neither by region; map created by the authors

smokefree public space policies. Specifically, the model's dependent variable of interest was a binary measure of whether each zip code had a policy protecting all indoor public spaces. Initially, we included the percentage of Blacks as an independent variable. However, we found that higher percentages of Black residents slightly increased the odds of having a smokefree public space policy. This seemed counter-intuitive, so we tested the inclusion of percentage White. This yielded a surprising decreased odds. We determined that because a lower proportion of the total Black population was covered by such a policy compared to other ethnic groups, but that having a high percentage of Blacks in a zip code indicated a higher likelihood of coverage, that perhaps ethnic heterogeneity was protective. We then investigated whether interaction terms improved the model fit, using the likelihood ratio test. Specifically, we examined interactions between ethnic heterogeneity and region, and between percentage black and region, and compared the log likelihoods obtained from models including and excluding these interaction parameters. Thus, our final model included the following independent variables: education, high/low ethnic heterogeneity, percentage white, income, and region, as well as an interaction term between ethnic heterogeneity and region. We accounted for nonindependence in zip code policy status within state clusters by fitting a hierarchical regression model including random effects at the state level. All statistical analyses were conducted using Stata v14 software.

\section{Results}

Of the approximately 350 million people living in the United States in 2014, 68\% had some form of smokefree public space policy protection within their home zip code (Table 1). A significant difference was observed between ethnic groups for the proportion covered $(p<0.001)$. Blacks had the lowest proportion of coverage, with only $58 \%$ of the population living in zip codes with any smokefree space policy, and Asians had the highest (82\%). Asians had the highest proportion of coverage (55\%) for policies banning smoking in indoor "public spaces generally", in comparison to Blacks (48\%) and Hispanics (38\%). These differences were significant $(p<0.001)$, and consistent with the differences found for policies covering the indoors of workplaces and restaurants.

For all types of smokefree spaces studied, Asian children had the highest proportion of coverage. Black and White children had the lowest proportions of coverage for policies restricting smoking at playgrounds, with only 21 and $22 \%$, respectively. In comparison, $38 \%$ of Hispanic children and $48 \%$ of Asian children had policy protection at playgrounds $(p<0.001)$. For coverage on school grounds, there was less difference by ethnicity (see Table 1). Overall, smokefree playgrounds and school 
Table 1 Percentage population covered by smokefree space area policies, by subgroups

\begin{tabular}{|c|c|c|c|c|c|c|c|}
\hline & Has any policy & Restaurants & Workplaces & Playgrounds & School grounds & $\begin{array}{l}\text { Both playgrounds and } \\
\text { school grounds }\end{array}$ & $\begin{array}{l}\text { Indoor public spaces } \\
\text { generally }\end{array}$ \\
\hline \multicolumn{8}{|l|}{ Ethnicity - Total population } \\
\hline Total & 68 & 64 & 66 & 28 & 18 & 9 & 50 \\
\hline Asian & 82 & 80 & 81 & 51 & 21 & 13 & 55 \\
\hline Black & 56 & 55 & 55 & 22 & 18 & 10 & 48 \\
\hline Hispanic & 68 & 64 & 67 & 40 & 16 & 9 & 38 \\
\hline White & 68 & 64 & 66 & 23 & 18 & 8 & \\
\hline Other & 77 & 74 & 76 & 44 & 19 & 12 & \\
\hline \multicolumn{8}{|l|}{ Ethnicity - Children $<15 y$} \\
\hline Total & 68 & 64 & a & 28 & 17 & 8 & \\
\hline Asian & 80 & 78 & & 48 & 21 & 12 & 56 \\
\hline Black & 58 & 55 & & 21 & 18 & & 49 \\
\hline Hispanic & 69 & 65 & & 38 & 15 & 7 & 38 \\
\hline White & 67 & 64 & & 22 & 18 & 8 & 53 \\
\hline Other & 77 & 74 & & 43 & 18 & & 46 \\
\hline \multicolumn{8}{|l|}{ Income ${ }^{b}$} \\
\hline$<\$ 25,000$ & 65 & 62 & 63 & 22 & 17 & 8 & 51 \\
\hline$\$ 25,000-\$ 75,000$ & 67 & 63 & 65 & 23 & 17 & 8 & 52 \\
\hline$>\$ 75,000$ & 71 & 67 & 69 & & 20 & 10 & 62 \\
\hline \multicolumn{8}{|l|}{ Educational Attainment ${ }^{\mathrm{b}}$} \\
\hline No high school diploma & 67 & 65 & 67 & & 19 & 7 & 61 \\
\hline High school diploma & 65 & 62 & & & 18 & 9 & 52 \\
\hline Bachelors & 70 & 66 & & & 20 & 10 & 53 \\
\hline Masters or Doctorate & 71 & 67 & & 29 & 21 & 11 & 55 \\
\hline \multicolumn{8}{|l|}{ Region - Total population } \\
\hline $\mathrm{AK} / \mathrm{HI}$ & 72 & 7 & 72 & 11 & $\sim 0$ & $\sim 0$ & 71 \\
\hline Midwest & 92 & 2 & 92 & 7 & 6 & 1 & 92 \\
\hline Northeast & 67 & & 65 & 43 & 51 & 39 & 61 \\
\hline Southeast & & & 32 & 8 & 10 & 1 & 31 \\
\hline Southwest & & 40 & 42 & 3 & $\sim 0$ & $\sim 0$ & 21 \\
\hline West & & 91 & 98 & 66 & 20 & 2 & 44 \\
\hline
\end{tabular}

$p$-values calculated using Pearson's $X^{2}$ statistic - all differences $p<0.001$

${ }^{a}$ not calculated as less relevant for children

${ }^{\mathrm{b}}$ calculated for the population over 25 years old

grounds were less common than smokefree indoor spaces. Only $8 \%$ of the total population lived in zip codes with protection in both playgrounds and school grounds, compared to $50 \%$ covered by policies restricting smoking in indoor "public spaces generally". Asian children had the highest proportion of such outdoor policy coverage (12\%).

We observed a gradient in coverage by some form of smokefree space policy by wealth, whereby those with the highest income ( $>75 \mathrm{k}$ ) were more likely to be covered $(71 \%)$, followed by the next income group (67\% of those earning $\$ 25-\$ 75 \mathrm{k}$ ), and then the lowest income group ( $65 \%$ of those earning $<\$ 25 \mathrm{k}$ ). These differences were statistically significant $(p<0.001)$. A similar and significant gradient was found for educational attainment, whereby the highest level of education (graduate degree) had the highest proportion covered by smokefree space policies (71\%) and the lowest levels of education (no high school diploma or only a high school diploma) had the lowest proportion (67\% for those without a high school diploma, $65 \%$ for those with a high school diploma).

By region, the Southeast had the lowest percentage of the population covered by any form of smokefree space policy (Table 1 and Fig. 1) with only 37\%. In contrast, the West had the highest coverage with $98 \%$ of the 
population covered, followed by the Midwest (92\%). The Northeast had significantly higher coverage at school grounds $(51 \%)$, compared to other regions $(p<0.001)$. No other region had more than $20 \%$ coverage, and Alaska/Hawaii and the Southwest had almost none of the population covered by these policies. The West had the highest coverage at playgrounds (66\%). The Northeast had a much higher rate of coverage for policies restricting smoking on both school grounds and playgrounds, compared to the other regions, with $39 \%$ of the population covered; no other region had more than $2 \%$ of the population covered. All regions had lower coverage on playgrounds and school grounds, compared to indoor public spaces.

Visually, there were clear geographic patterns in smokefree space policies, whereby most states either had state smokefree space policies covering all indoor public spaces or had no state wide policies in place (Fig. 1). Regions without state wide smokefree space policies exhibit patchworks of policy adoption, particularly in the Southeast. In terms of smokefree space policies at school grounds and playgrounds (Fig. 2), there appeared to be less consistency at the state-level. Clusters of jurisdictions which have adopted policies restricting smoking on both school grounds and playgrounds can be observed, particularly in Mississippi, New Jersey, Colorado, and Oregon. New York is the only state covered for both types of areas. Nineteen states had no indoor or outdoor smokefree space policy at the state level (although West Virginia was largely covered by county-level policies) and only 10 states had a state policy on either playgrounds or school grounds.

In the mixed effects logistic regression model (Table 2), income, education, percentage white and ethnis heterogeneity and the interaction term were all found to be significant predictors of whether a smokefree space policy had been adopted for all indoor "public spaces generally". We observed a gradient whereby increased wealth was significantly associated with smokefree policy legislation, after adjustment for other covariates. The highest income group had more than double the odds of having a policy, compared to the lowest income group (OR 2.55, 95\%CI: 2.06-3.14). We found small, significant effects for both percentage of the population without a high school diploma and percentage white, whereby higher percentages were associated with not having a policy. We also found that the effect of high ethnic heterogeneity differed significantly by region, but was consistently positively associated with having a policy $(p=0.004)$. For example, the ratio of odds of having a policy in zip codes with high versus low heterogeneity was highest in Alaska/Hawaii (OR 7.8), followed by the Midwest (OR 4.93), followed by the Southwest and

Table 2 Hierarchical logistic regression model results

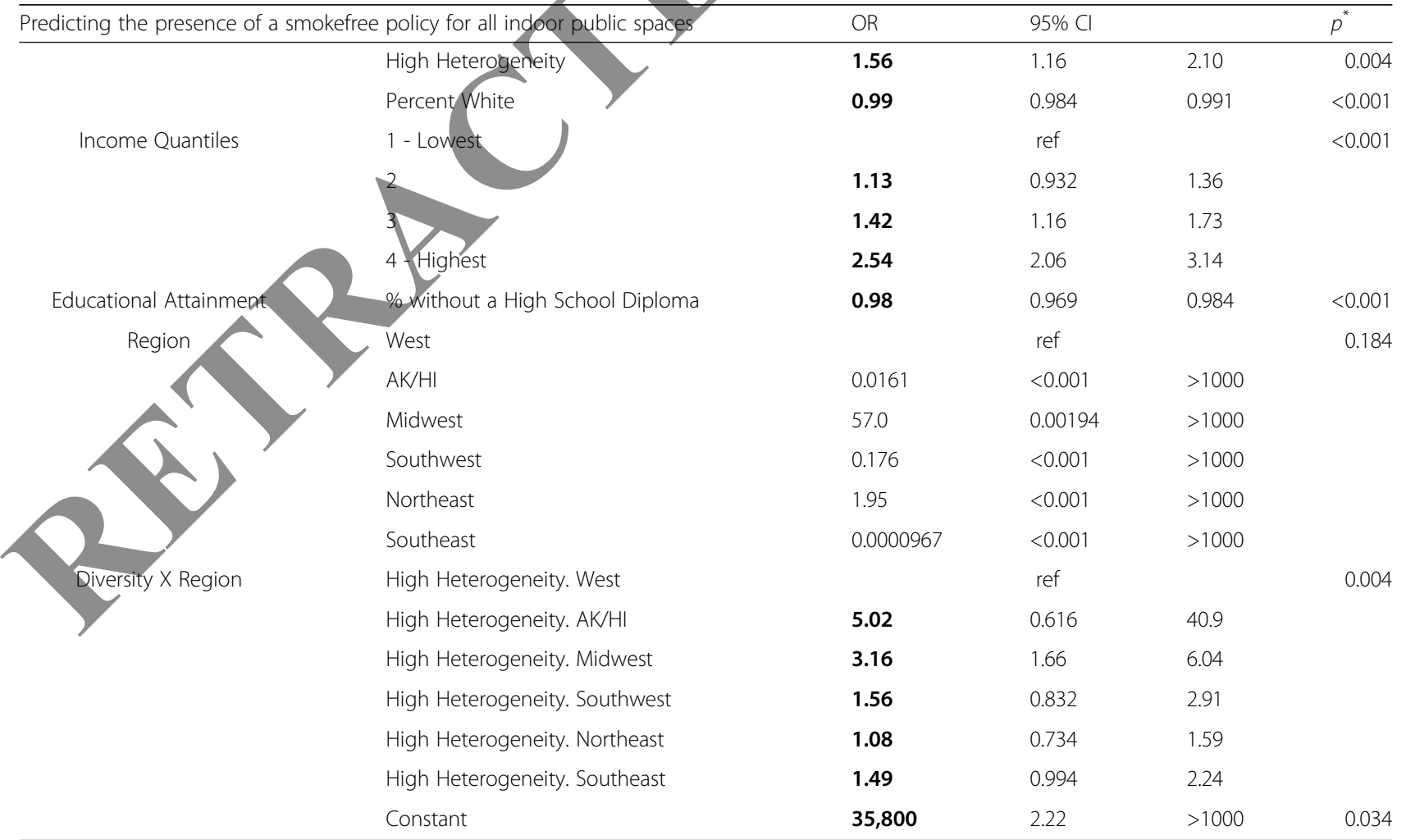

"Overall $p$-values for categorical variables calculated using likelihood ratio test Bold indicates significance at the $p<0.05$ level 
Southeast (OR 2.4 and 2.3, respectively), Northeast (OR 1.7) and the West (OR 1.6).

\section{Discussion}

Our findings confirm that there are stark differences in smokefree space policy coverage based on ethnicity, socioeconomic status, educational attainment, and region. As Gonzalez et al. [33] found for indoor policies, Blacks in the United States typically had lower rates of coverage for all the types of spaces that we studied. Only $56 \%$ of Blacks had any form of policy coverage in their zip code, well below the national average of $68 \%$. Asians had the highest proportion of policy coverage across all spaces. Such differences in coverage may perpetuate health inequalities and differences in the normality of smoking by ethnicity. The results are consistent with previous findings, that aspects of smoking and efforts to reduce the damage of tobacco use often impact different subgroups in different ways. Ethnic heterogeneity was found to be a significant predictor of the adoption of policies protecting all indoor public spaces, with more ethnically diverse zip codes more likely to have policy protection.

A serious lack of smokefree policy protection exists for children in the United States; only $8 \%$ of children in the United States live in zip codes with both smokefree playgrounds and school grounds. This low joint coverage is regardless of ethnicity. It is important to eliminate exposure to tobacco use for children for three main reasons. Reducing exposure to tobacco use serves to reduce both the social normality and acceptability of smoking, as well as exposure to SHS. Furthermore, ethnic inequalities in coverage of playground policies may contribute to long-term health inequalities. The differences in the coverage spread for playgrounds (where there was a wide coverage variance by ethnicity) and school grounds (where there was a much narrower spread) may be related to different authorities covering the different types of child-related areas. Although playground and school ground policies are comparatively rare, these policies have, been supported by $76 \%$ or more of the public in surveys within the USA since 2005 [35].

Regional differences in the coverage of smokefree space policies were large - and the effect of ethnic heterogeneity varied. Only $37 \%$ of people living in the Southeast have any form of policy coverage, compared to $98 \%$ in the West and $92 \%$ in the Midwest. Considering the importance of smokefree space policy in reductions in tobacco prevalence and normality, it is crucial to address regional differences in order to continue to see equitable declines in tobacco use. These large regional discrepancies help to explain some of the differences in coverage by ethnicity, considering that more African Americans live in the Southeast, compared to other regions of the United States. Lower levels of coverage in the Southeastern United States are also likely related, in part, to the economic geography of tobacco; the largest tobacco producing states are all in the Southeast. There is a large discrepancy between the Northeast and the rest of the United States, in the coverage for both playgrounds and school grounds, which warrants further study. The Northeast had coverage at a rate of 39\% (largely due to New York State), compared to less than 2\% for the rest of the country. The effect of ethnic heterogeneity was significantly different by region, but was consistent in that more heterogeneous zip codes had higher odds of coverage in every region. Ethnic heterogeneity played the largest role in Alaska and Hawaii. Of the lower 48 states, the Midwest showed the largest effect of ethnic heterogeneity, with diverse zip codes almost five times as likely of having a policy. Ethnic heterogeneity showed the least effect in the West, however diverse zip codes there were still $60 \%$ more likely to have policies.

This research found evidence of inequalities in smokefree space policy coverage by socioeconomic status and by educational attainment. In particular, the odds of having a policy covering all indoor public spaces were found to decrease as the proportion of the population without a high school diploma increased, and as the average income of the zip code decreased. These differences illustrate ongoing shortages in protection for the United States' poorest and least educated citizens, which begin at birth and impact the likelihood of smoking.

\section{Research implications}

Considering the inequities observed in this study, the forces which impact policy adoption are an important next step to research. Successful adoption of policies is likely due in part to differing political climates between areas, as well as efforts by both the tobacco industry and by smokefree advocates [36-38]. Our speculation is that smokefree advocate organizations have a greater relative impact in cities compared to tobacco marketing. Urban areas are known to lean towards voting for Democrats, have more robust public health systems, and generally be more accepting of government oversight and legislature [32, 39, 40]. Future research could explore relationships between population density and policy adoption.

\section{Policy implications}

In order to further declines in smoking, policies must address the low level of coverage in places frequented by youth. Considering the impact these policies have on the perceptions of smoking which children develop, as well as the low existing level of coverage nationally, policies aimed at protecting children in playgrounds would have a large impact on smoking trends, now and into the future. 


\section{Conclusion}

This research revealed clear inequalities in the coverage of smokefree space policies, specifically ethnic, income, educational and regional inequalities. These inequalities may perpetuate the normality of smoking within subgroups of the United States' population, and thus reinforce disparities in the negative impacts of exposure to smoking. Our regression results indicate that income inequalities between places may influence smokefree policies, and that policy coverage differences have real potential to exacerbate existing health inequalities. Legislative coverage of smokefree spaces is an important, cost-effective option to protect adults and children from SHS exposure and the normality of smoking. But, if not implemented equitably, tobacco-related health inequities may persist.

\section{Acknowledgements}

The tobacco control laws data were provided by the American Nonsmokers' Rights Foundation U.S. Tobacco Control Laws Database@.

\section{Funding}

This work received funding support from Michigan State University's Provost Undergraduate Research Initiative. The funding body was not involved in the design of the study, collection of data, analysis or interpretation of data or the writing of the manuscript.

\section{Availability of data and materials}

The 2010 census data used in this study is publically-available from the government and available for download at: https://www.census.gov/2010 data/. Smokefree policy data is both freely available (http://www.no-sm goingsmokefree.php?id=519\#outdoor) and available for purchase dataset form from American Nonsmokers' Rights Foundation.

\section{Authors' contributions}

GT and AP designed the study. GT obtained the policy data. CL obtalned the census data. AP supervised analyses and guided interpretation, conducted by $C L$. All authors read and approved the manuscript.

\section{Competing interests}

The authors declare that they have no competing interests.

Consent for publication

Not applicable.

Ethics approval and consent to participate

Not applicable.

\section{Publisher's Note}

Springer Nature remains neutral with regard to jurisdictional claims in published maps and institutional affiliations.

\section{Author details}

${ }^{1}$ Department of Geography, Environment, and Spatial Sciences, Michigan State University, East Lansing, MI 48824, USA. ²Department of Public Health University of Otago, Wellington 6021, New Zealand. ${ }^{3}$ Environmental Science and Policy Program, Michigan State University, East Lansing, MI 48824, USA.

Received: 5 December 2016 Accepted: 7 May 2017

Published online: 16 May 2017

\section{References}

1. World Health Organization, Tobacco: fact sheet N³39; 2015

2. U.S. Department of Health and Human Services, The health consequences of smoking - 50 years of progress. A report of the surgeon general. 2014.
3. Boyle P. Tobacco and public health: science and policy. USA: Oxford University Press; 2004

4. Parkin D. 1. The fraction of cancer attributable to lifestyle and environmental factors in the UK in 2010. Br J Cancer. 2011;105:S2-5.

5. Barnett R, Pearce J, Moon G. Community inequality and smoking cessation in New Zealand, 1981-2006. Soc Sci Med. 2009:68(5):876-84.

6. Moore S, Stewart S, Teixeira A. Decomposing social capital inequalities in health. J Epidemiol Community Health. 2014;68(3):233-8.

7. Jamal A, King BA, Neff LJ, Whitmill J, Babb SD, Graffunder CM. Current Cigarette Smoking Among Adults — United States, 2005-2015. MMWR Morb Mortal Wkly Rep. 2016;65:1205-11.

8. Nguyen KH, Marshall L, Brown S, Neff L. State-Specific Rrevalence of Current Cigarette Smoking and Smokeless Tobacco Use Among Adults - United States, 2014. MMWR Morb Mortal Wkly Rep. 2016;65:1045-51.

9. Lawrence EM, Pampel FC, Mollborn S. Life course transitions and racial and ethnic differences in smoking prevalence. Adv Life Course Res. 2014;22:27-40.

10. Kruger J, et al. Smoke-free home and Vehicle rules by tobacco use status among US adults. Prev Med. 2015;78:9-13.

11. Aloise-Young PA, Cruickshank C, Chavez EL. Cigarette smoking and perceived health in school dropouts: a comparison of Mexican American and non-Hispanic white adolescents. J Pediatr Psychol. 2002;27(6):497-507.

12. Grant JD, et al. Associations of alcohol, picotine, cannabis, and drug use/ dependence with educational attainment: evidence from Cotwin-control analyses. Alcohol Clin Exp Res. 2012;36(8):1412-20.

13. Reid $J$, Hammond D, Driezen P. Socio-economic status and smoking in Canada, 1999-2006: has there been any progress on disparities in tobacco use? Canadian Can J Public Health. 2010;101(1):73-8.

14. Leonardi-Bee J, Jere ML, Britton J. Exposure to parental and sibling smoking and the risk of smoking uptake in childhood and adolescence: a systematic review and meta-analysis. Thorax. 2011;66:847-55.

5. Baha M, Le Faou A-L. Smokers' reasons for quitting in an anti-smoking social context. Public Health. 2010;124(4):225-31.

DiFranza JR, et al. Tobacco promotion and the initiation of tobacco use: sessing the evidence for causality. Pediatrics. 2006;117(6):e1237-48.

MacFadyen L, Hastings G, MacKintosh AM. Cross sectional study of young people's awareness of and involvement with tobacco marketing. BMJ. 2001;322(7285):513-7.

18. Pierce JP, White VM, Emery SL. What public health strategies are needed to reduce smoking initiation? Tob Control. 2012;21(2):258-64.

19. Centers for Disease Control and Prevention, Tobacco industry marketing. 2016.

20. Klein EG, Bernat DH, Forster JL. Young adult perceptions of smoking in outdoor park areas. Health Place. 2012;18(5):1042-5.

21. Albers $A B$, et al. Effect of smoking regulations in local restaurants on smokers' anti-smoking attitudes and quitting behaviours. Tob Control. 2007;16(2):101-6.

22. U.S. Department of Health and Human Services, Preventing tobacco use among youth and young adults: a report of the surgeon general: executive summary. 2012.

23. Hahn EJ. Smokefree legislation a review of health and economic outcomes research. Am J Prev Med. 2010;39(6):S66-76.

24. Zablocki RW, et al. Smoking ban policies and their influence on smoking behaviors among current California smokers: a population-based study. Prev Med. 2014:59:73-8.

25. Chahine T, Subramanian S, Levy Jl. Sociodemographic and geographic variability in smoking in the US: a multilevel analysis of the 2006-2007 current population survey, tobacco use supplement. Soc Sci Med. 2011;73(5):752-8.

26. Chaiton $\mathrm{M}$, et al. Exposure to smoking on patios and quitting: a population representative longitudinal cohort study. Tob Control. 2014;0:1-6.

27. Nykiforuk Cl, Eyles J, Campbell HS. Smoke-free spaces over time: a policy diffusion study of bylaw development in Alberta and Ontario, Canada. Health Soc Care Community. 2008;16(1):64-74.

28. Hyland A, Barnoya J, Corral JE. Smoke-free air policies: past, present and future. Tob Control. 2012;21(2):154-61.

29. American Non-Smokers Rights Foundation, U.S. tobacco control Laws database: research applications. 2010.

30. American Lung Association in California, Becoming a policy wonk on comprehensive outdoor secondhand smoke ordinances: answers to tough questions from opponents and elected officials. 2014.

31. Bayer R, Bachynski KE. Banning smoking in parks and on beaches: science, policy, and the politics of denormalization. Health Aff. 2013;32(7):1291-8. 
32. Hood, N.E., et al., Community characteristics associated with smokefree park policies in the United States. Nicotine Tob Res, 2014. 16(6): p. 828-835.

33. Gonzalez M, et al. Strong smoke-free law coverage in the United States by race/ethnicity: 2000-2009. Am J Public Health. 2013;103(5):e62-6.

34. Wadsworth T, Kubrin CE. Structural factors and black interracial homicide: a new examination of the causal process. Criminology. 2004;42(3):647-72.

35. Thomson G, et al. Attitudes to smoke-free outdoor regulations in the USA and Canada: a review of 89 surveys. Tob Control. 2015;0:1-11.

36. Rayens MK, et al. Political climate and smoke-free laws in rural Kentucky communities. Policy Polit Nurs Pract. 2012;13(2):90-7.

37. Satterlund TD, et al. Barriers to adopting and implementing local-level tobacco control policies. J Community Health. 2011;36(4):616-23.

38. Tung GJ, et al. Political factors affecting the enactment of state-level clean indoor air laws. Am J Public Health. 2014;104(6):e92-7.

39. Harris JK, Mueller NL. Policy activity and policy adoption in rural, suburban, and urban local health departments. J Public Health Manag Pract. 2013:19(2):E1-8.

40. Rosenblatt RA, Casey S, Richardson M. Rural-urban differences in the public health workforce: local health departments in 3 rural western states. Am J Public Health. 2002;92(7):1102-5.

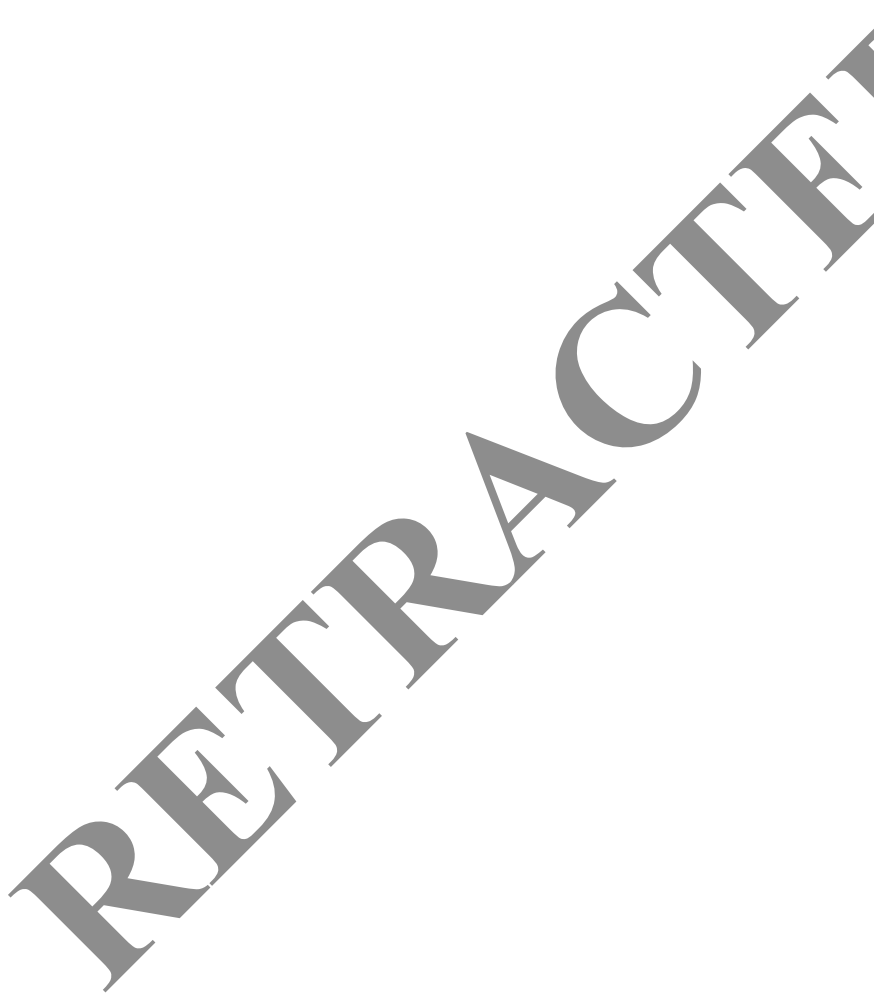

Submit your next manuscript to BioMed Central and we will help you at every step:

- We accept pre-submission inquiries

- Our selector tool helps you to find the most relevant journal

- We provide round the clock customer support

- Convenient online submission

- Thorough peer review

- Inclusion in PubMed and all major indexing services

- Maximum visibility for your research

Submit your manuscript at www.biomedcentral.com/submit

) Biomed Central 